www.nature.com/ejhg

\title{
ARTICLE
}

\section{CFTR gene mutations in sarcoidosis}

\author{
Manfred Schürmann ${ }^{1}$, Melanie Albrecht ${ }^{1,3}$, Eberhard Schwinger ${ }^{1}$ and \\ Manfred Stuhrmann*,2
}

${ }^{1}$ Institute of Human Genetics, Medical University Lübeck, Lübeck, Germany' ${ }^{2}$ Institute of Human Genetics, Medical School Hannover, Hannover, Germany ${ }^{3}$ Department of General Internal Medicine, Christian-Albrechts-Universtität Kiel, Germany

Sarcoidosis is a complex disease of multiorgan granulomatous inflammation. Genetic susceptibility is involved in the pathogenesis of the disorder. Two successive studies from Italy have shown a high frequency of mutations of the cystic fibrosis transmembrane conductance regulator (CFTR) gene in patients suffering from sarcoidosis. We have genotyped a panel of 63 families with two or more affected siblings for the CFTR gene mutation R75Q, which was found to be present in three of 26 cases of the Italian study. Although R75Q was present in seven families, it was neither associated with the sarcoidosis phenotype in the German population $(P=0.5)$, nor was it linked to sarcoidosis $(P=0.54)$. In addition, a screening for 34 functional CFTR mutations was performed in a subset of 54 patients from 25 families. These patients were known to be concordant for at least one parental copy of the CFTR gene. With the exception of the mayor CF mutation $\Delta \mathrm{F} 508$, which was present in three patients and absent in one patient from two families, we did not find any other CF mutation in these 54 patients. Our results do not support the hypothesis that CFTR mutations have a major influence on the pathogenesis of sarcoidosis. European Journal of Human Genetics (2002) 10, 729-732. doi:10.1038/sj.ejhg.5200868

Keywords: sarcoidosis; CFTR gene mutations; family study

\section{Introduction}

Sarcoidosis is a generalised inflammatory disorder with increased macrophage and CD4+ T cell activity and granuloma formation in a variety of organs. The lungs and intrathoracic lymph nodes are the sites that are primarily affected, and eyes, joints, skin and heart are often involved. Sarcoidosis occurs mainly in young adults with a prevalence rate of approximately five in 10000 in Germany. The course of the disease is highly variable, and ranges from complete healing within months in approximately one of three patients, to progressive damage of affected organs in one of 10 patients. ${ }^{1,2}$ Differences of the prevalence rates between ethnic groups and occasional clustering in families support the assumption of a genetic predisposition. ${ }^{3}$ According to current concepts, an exogenous, assumedly

\footnotetext{
*Correspondence: Manfred Stuhrmann; Institute of Human Genetics, Medical School Hannover, Carl-Neuberg-Str. 1, D-30625 Hannover Germany. Tel: ++49-5115323719; Fax: ++49-5115325865;

E-mail: stuhrmann.manfred@mh-hannover.de

Received 29 April 2002; revised 21 June 2002; accepted 28 June 2002
}

inhaled agent triggers an unbalanced immune response in susceptible individuals. ${ }^{4}$

Numerous studies have been performed to identify gene variants that could predispose to sarcoidosis. Previously, we have conducted a genome-wide search for predisposing genes in 63 German sarcoidosis families with 138 affected siblings that revealed evidence of linkage to the MHC gene region. ${ }^{5,6}$ On chromosome 7 , non-parametric LOD scores of $1.89(P=0.03)$ and $1.47(P=0.07)$ were obtained for the microsatellite markers D7S821 and D7S1842 that flank the CFTR gene at a distance of 10 and $9 \mathrm{cM}$, respectively. Two successive studies from Italy reported a high frequency of CFTR mutations in individuals suffering from sarcoidosis. ${ }^{7,8}$ The most frequent CFTR mutation was $\mathrm{R} 75 \mathrm{Q}$, which was present in three of 26 cases. $^{8}$ These findings prompted us to screen the panel of 63 families with two or more patients for R75Q. Additionally, 54 patients from 25 families, who are concordant with their affected sibling for at least one parental copy of the CFTR gene (as derived from chromosome $7 \mathrm{q}$ microsatellite haplotypes $)^{6}$ were tested for 34 further mutations of the CFTR gene. 


\section{Subjects and methods}

The study population consisted of 63 German families with siblings suffering from sarcoidosis, drawn from a DNA bank of sarcoidosis families (233 Caucasian, German individuals; 138 patients, 42 unaffected siblings and 53 parents). Details of these families are listed in Table 1, and further details are given in an earlier report on a genome-wide microsatellite marker linkage scan. ${ }^{6}$ Sarcoidosis was confirmed by biopsy in 101 of 138 patients, and for the remaining 37 patients the clinical course was consistent with that of sarcoidosis. Based on microsatellite marker haplotype information (D7S820, D7S821, D7S1842, D7S1824, D7S3070) from the genome-wide genotype analysis, affected siblings were identified who have at least one parental chromosome 7 CFTR gene region in common. These patients were re-contacted, and 54 of 57 patients agreed to take part in a detailed CFTR genotype analysis. This subset of patients represented 25 families (three, seventeen, three, and two families represented by one, two, three, and four patients, respectively). All participants gave written informed consent for participation in the study, and the investigation was approved by the institutional ethical review board.

The complete panel (63 families) was genotyped for the CFTR gene mutation R75Q by PCR with primers $3 \mathrm{i}-5$ and $3 \mathrm{i}-3$ (according to ref $^{9}$ ) and restriction enzyme digestion of the corresponding PCR products. R75Q $(\mathrm{G} \rightarrow \mathrm{A}$ at nucleotide position 356) creates a new Bsr DI cleavage site in the mutated gene sequence. DNA from a R75Q heterozygous subject from a previous study ${ }^{10}$ was used as control DNA. The subset of 54 patients was analysed for 34 mutations of the CFTR gene that are known to affect the function of the gene. Initially, the samples were screened for the most frequent CF mutation $\Delta \mathrm{F} 508$ and for other deletions or insertions such as $\Delta \mathrm{I} 507$ or 1677 delTA by PCR and polyacrylamide gel electrophoresis. ${ }^{11}$ Using the Inno-Lipa CFTR 12 and CFTR 17+Tn line probe assays (Innogenetics, Ghent, Belgium), we screened 45 of the samples for 27 further CFTR mutations and IVS8-5T (5T allele). The remaining nine samples were tested with ARMS technology (ELUCI-

Table 1 Details of the structure of 63 families with siblings suffering from sarcoidosis

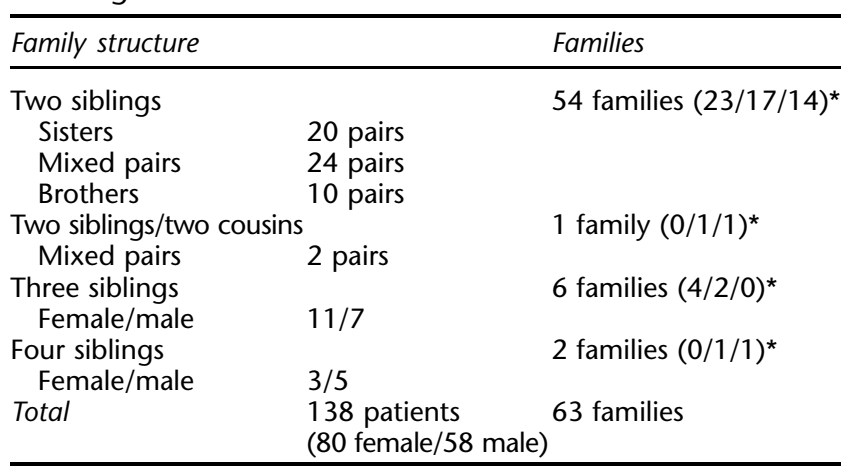

*With (no/one/two) parents included in the study.
GENE CF20 and ELUCIGENE CF polyT, Zeneca Diagnostics, Oxfordshire, UK) for 18 further mutations and IVS8-5T. The mutation spectra of both commercially available kits (Innogenetics and Zeneca) overlap each other to a high extent (for details please refer to the suppliers' protocols). A list of the corresponding mutations with detailed frequencies in the German population is given in ref. ${ }^{12}$ Finally, we tested all 54 samples for the presence of I336K, Y1092X, 3272-26A $\rightarrow \mathrm{G}$ and CFTRdel2,3 $(21 \mathrm{~kb})$ by PCR and restriction enzyme digestion with the respective enzymes (for mutation references, refer to the Cystic Fibrosis Genetic Analysis Consortium database). Using this method, we are normally able to detect more than $90 \%$ of CF mutations among German CF patients. ${ }^{12,13}$ Differences in the genotype frequencies between patients and controls were assessed by Fisheŕs exact test, and non-parametric linkage analysis was performed using Genehunter 2.0. ${ }^{14}$

\section{Results}

R75Q was identified in eight patients, three parents and in one unaffected sibling from a total of seven families. In these families, R75Q was not present in 13 patients, six parents, nor in three unaffected siblings. In six of the seven families at least one affected sibling was negative for R75Q. The frequency of R75Q heterozygosity in the group of unrelated founders (parents) was 0.057 (three in 53), which was slightly higher but statistically not significantly different ( $P=0.5$; Fisher's exact test) from the frequency of 0.011 (four in 94) among healthy German controls. ${ }^{10}$ The frequency for R75Q among patients was 0.05 (eight in 138), which was statistically neither different compared to the group of healthy controls $(P=0.43)$ nor to the parents $(P=0.64)$ nor to the healthy siblings $(P=0.35)$. To stratify for non-related patients, we randomly selected one patient from each family. Again, the frequency among patients (0.031; two in 63) did not differ $(P=0.55)$ from the frequency among controls. We conclude that R75Q is not associated with sarcoidosis in our study group. In addition, we did not obtain any evidence for linkage between sarcoidosis and R75Q by linkage analysis. Actually, non-parametric two point linkage analysis using Genehunter 2.0 resulted in an NLP score of $-0.11(P=0.54)$. To conclude it can be said that, R75Q and the sarcoidosis phenotype segregate as independent traits (Figure 1).

In the subset of 54 patients from 25 families, who are concordant with their affected sibling for at least one parental copy of the CFTR gene, no mutation other than the $\Delta$ F508 deletion was identified. Three patients from two families were heterozygous for $\Delta \mathrm{F} 508$, a finding consistent with the presumed $\Delta \mathrm{F} 508$ carrier frequency of approximately one in 35 in the German general population. In one of the two families the pair of siblings suffering from sarcoidosis was concordant for the $\Delta \mathrm{F} 508$ carrier status and in the other it was discordant. 


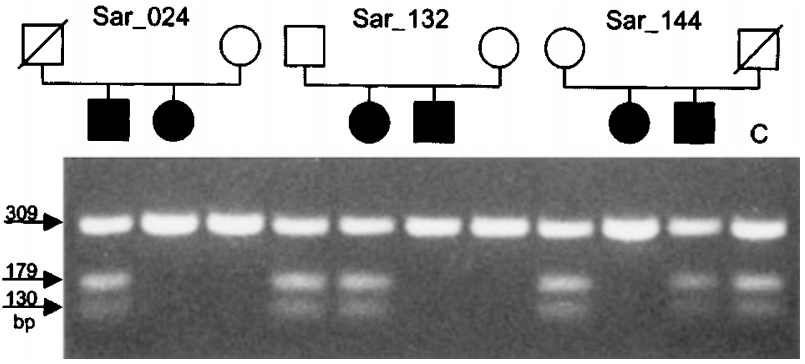

Figure 1 Detection of R75Q (356G/A) by PCR and restriction digestion in three families. In each of the families Sar024, Sar132 and Sar144, one male and one female sibling are affected with sarcoidosis (black symbols). PCR products with primers encompassing $\mathrm{R} 75 \mathrm{Q}$ were digested with the restriction enzyme $B s r$ DI and visualised by agarose gel electrophoresis. The PCR product of the common allele (G) does not contain a Bsr DI restriction site and is represented by a single band of $309 \mathrm{bp}$ (size of the uncleaved PCR product). The rare allele (A) contains a Bsr DI site and is represented by two bands of 179 and $130 \mathrm{bp}$. In each of the three families, only one of the affected siblings is heterozygote for R75Q (three bands), while the other affected siblings are homozygous for the $\mathrm{G}$ allele (one band). Lane C: Bsr DI digested PCR product from R75Q heterozygous control DNA.

\section{Discussion}

Sarcoidosis is a complex disorder. Exogenous as well as inherited components are assumed to be involved in the development and progression of the characteristic granulomatous inflammation. The contribution of predisposing genes is demonstrated by the recurrence of the disease within families. Based on a nation-wide thoracic radiographic screening programme in Germany, Jörgensen found pulmonary sarcoidosis in 39 first-degree relatives out of a total of 2471 cases. ${ }^{15}$ Kirsten performed a questionnaire inquiry of the German patients' organisation, the Deutsche Sarkoidose-Vereinigung, and found a familial recurrence of sarcoidosis in 36 close relatives of 621 people that responded. ${ }^{16}$ These data match a recurrence risk of roughly one in 100 for first degree relatives, contrasting to a prevalence rate of approximately five in 10000 in the general German population.

To test the hypothesis that mutations in the CFTR gene may represent one of the genetic factors, which predispose to sarcoidosis, we focused our attention on a panel consisting of 63 families, each one including two or more affected siblings. We identified the CFTR mutation R75Q in seven families but could not find any evidence, which would prove that this mutation has a predisposing effect on the disease, neither by association nor by linkage analysis. Instead, R75Q segregated independently from the sarcoidosis phenotype in these families. Previously, we and others reported a relatively high frequency of R75Q among patients with congenital absence of the vas deferens (CAVD), ${ }^{10,17,18}$ bronchiectasis, ${ }^{7,19}$ atypical mild cystic fibrosis, $^{20}$ chronic idiopathic pancreatitis, ${ }^{21}$ allergic bronchopulmonary aspergillosis, ${ }^{22}$ and sarcoidosis. ${ }^{7,8}$ Bombieri et al. concluded from their study that R75Q may be a CFTR gene mutation characteristic of sarcoidosis. ${ }^{8}$ Our results do not support this hypothesis. Moreover, $\mathrm{R} 75 \mathrm{Q}$ is listed as a polymorphism (356G/A) in the Cystic Fibrosis Genetic Analysis Consortium database. The exact role of $\mathrm{R} 75 \mathrm{Q}$ still remains unclear, but the results from the studies mentioned above suggest that R75Q may be associated with mild CF symptoms.

To further address the question of an involvement of CFTR mutations in the pathogenesis of sarcoidosis, we referred back to the genotype data of our previous genome scan $^{6}$ and identified siblings concordant for at least one parental CFTR gene. These siblings formed a most informative group of patients for the study of CFTR gene mutations in sarcoidosis. The set of assays that we used in our study normally detects approximately 90 of 100 mutated CFTR genes in the German population. ${ }^{12,13}$ With the exception of $\Delta F 508$, we did not find any of the 34 pathogenic CFTR mutations amongst the sarcoidosis patients. The observed frequency of the $\Delta \mathrm{F} 508$ mutation was close to the expected value, and the segregation pattern was compatible with that of independent segregation. In conclusion, our results do not support the hypothesis that CFTR gene mutations contribute significantly to the development of sarcoidosis.

In addition, one should consider that if carriers of CFTR mutations are over-represented among sarcoidosis patients, one would expect an increased prevalence of cystic fibrosis in their families. Although there are a few reports of patients affected with both CF and sarcoidosis, ${ }^{23,24}$ we are not aware of any German family that shows the coexistence of sarcoidosis and cystic fibrosis, even though this issue and our results have been discussed in the journal of the German patients' organisation that has been sent to approximately 3000 patients.

On the other hand, the results of our study do not mean that the CFTR gene is irrelevant in the pathogenesis of sarcoidosis. Sarcoidosis shows a considerable degree of variability with respect to its clinical and epidemiological characteristics. There seems to be a significant gradient in sarcoidosis prevalence rates in Europe with higher rates in the north-western region, but standardised epidemiological information is missing. However, there is convincing evidence of geographical differences in the clustering of sarcoidosis within families. Extended multicase families have been reported from Sweden. ${ }^{25}$ An increased recurrence risk has been shown for Germany, ${ }^{15,16}$ The Netherlands, ${ }^{26}$ United Kingdom, ${ }^{27}$ and the Irish Republic, ${ }^{28}$ while the phenomenon is virtually absent in Spain. ${ }^{29}$ It is not clear whether or not clustering is a characteristic of a specific type of sarcoidosis different from the sporadic disease represented by the study population of the Italian report. If this were true, then the methods that we used to test the hypothesis derived from the Italian study, would have been prone to fail. Clearly, a concerted Europe-wide approach 
would be highly desirable to clarify the contrasting results concerning the importance of CTFR gene mutations in sarcoidosis.

\section{Acknowledgements}

We thank Andrea Korte for technical assistance and Nicola Meyer for reading the manuscript. We especially thank the patients and their families who participated in this study. The patients' organisation Deutsche Sarkoidose-Vereinigung contributed essentially to the recruitment of families. Professor Wurm, Dr Kögler and Dr Dieringer (Höchenschwand), Professor Müller-Quernheim (Freiburg), Professor Costabel (Essen), Professor Kirsten (Großhansdorf), Professor Liebetrau (Lostau), Dr Vorderstrasse (Bremen), and many others supported us, by acquainting us with additional families. The study was funded in part through the German National Genome Research Network (NGFN) and its clinical network 'Inflammation and Environment' (grant 01 GS 01160101-01 GS 0121).

\section{References}

1 ATS Board of Directors, ERS Executive Committee: Statement on sarcoidosis - Joint Statement of the American Thoracic Society (ATS), the European Respiratory Society (ERS) and the World Association of Sarcoidosis and Other Granulomatous Disorders (WASOG) adopted by the ATS Board of Directors and by the ERS Executive Committee, February 1999. Am J Respir Crit Care Med 1999; 160: 736-755.

2 Müller-Quernheim J: Sarcoidosis: immunopathogenetic concepts and their clinical application. Eur Respir J 1998; 12: 716-738.

3 Luisetti M, Beretta A, Casali L: Genetic aspects in sarcoidosis. Eur Respir J 2000; 16: 768 - 780.

4 McGrath DS, Goh N, Foley PJ, du Bois RM: Sarcoidosis: genes and microbes soil or seed?. Sarcoidosis Vasc Diffuse Lung Dis 2001; 18: 149-164.

5 Schürmann M, Lympany PA, Reichel P et al: Familial sarcoidosis is linked to the major histocompatibility complex region. $\mathrm{Am}$ Respir Crit Care Med 2000; 162: 861-864.

6 Schürmann M, Reichel P, Müller-Myhsok B, Schlaak M, MüllerQuernheim J, Schwinger E: Results from a genome-wide search for predisposing genes in sarcoidosis. Am J Respir Crit Care Med 2001; 164: 840-846.

7 Bombieri C, Benetazzo M, Saccomani A et al: Complete mutational screening of the CFTR gene in 120 patients with pulmonary disease. Hum Genet 1998; 103: 718-722.

8 Bombieri C, Luisetti M, Belpinati F et al: Increased frequency of CFTR gene mutations in sarcoidosis: a case/control association study. Eur J Hum Genet 2000; 8: 717-720.

9 Zielenski J, Rozmahel R, Bozon D et al: Genomic DNA sequence. of the cystic fibrosis transmembrane conductance regulator (CFTR) gene. Genomics 1991; 10: 214-228.
10 Dörk T, Dworniczak B, Aulehla-Scholz C et al: Distinct spectrum of CFTR gene mutations in congenital absence of vas deferens. Hum Genet 1997; 100: $365-377$.

11 Stuhrmann M, Schmidtke J: PCR-based mutation analysis in cystic fibrosis. Ann Med 1992; 24: 183-185.

12 Stuhrmann M, Dörk T: Mutationsanalytik der Mukoviszidose;; in Zabransky S (ed.) Screening auf angeborene endokrine und metabolische Störungen. Wien, New York: Springer, 2001, pp 297-326.

13 Dörk T, Mekus F, Schmidt K et al: Detection of more than 50 different CFTR mutations in a large group of German cystic fibrosis patients. Hum Genet 1994; 94: 533-542.

14 Kruglyak L, Daly MJ, Reeve-Daly MP, Lander ES: Parametric and nonparametric linkage analysis: a unified multipoint approach. Am J Hum Genet 1996; 58: 1347-1363.

15 Jörgensen G: Die Genetik der Sarkoidose. Acta Med Scand 1964; 425 (Suppl): 209-212.

16 Kirsten D: Sarcoidosis in Germany. Analysis of a questionnaire survey in 1992 of patients of the German Sarcoidosis Group. Pneumologie 1995; 49: 378-382.

17 Chillon M, Casals T, Mercier B et al: Mutations in the cystic fibrosis gene in patients with congenital absence of the vas deferens. $N$ Engl J Med 1995; 332: 1475 - 1480.

18 Oates R, Amos J: Congenital bilateral absence of the vas deferens. A genetic commonality. World J Urol 1993; 11: 82-88.

19 Girodon E, Cazeneuve C, Lebargy F et al: CFTR gene mutation in adults with disseminated bronchiectasis. Eur J Hum Genet 1997; 5 $149-155$.

20 Hughes D, Dörk T, Stuhrmann M, Graham C: Mutation and haplotype analysis of the CFTR gene in atypically mild cystic fibrosis patients from Northern Ireland. J Med Genet 2001; 38 $136-139$.

21 Ockenga J, Stuhrmann M, Ballmann M et al: Mutations of the cystic fibrosis gene, but not cationic trypsinogen gene, areassociated with recurrent or chronic idiopathic pancreatitis. Am J Gastroenterol 2000; 95: 2061-2067.

22 Weiner Miller P, Hamosh A, Macek M Jr et al: Cystic fibrosis transmembrane conductance regulator (CFTR) gene mutations in allergic bronchopulmonary aspergillosis. Am J Hum Genet 1996; 59: $45-51$.

23 Soden M, Tempany E, Bresnihan B: Sarcoid arthropathy in cystic fibrosis. Br J Rheumatol 1989; 28: 341-343.

24 Rettinger SD, Trulock EP, Mackay B, Auerbach HS: Sarcoidosis in an adult with cystic fibrosis. Thorax 1989; 44: 829-830.

25 Wiman LG: Familial occurrence of sarcoidosis. Scand J Resp Dis 1972; 80 (Suppl): $115-119$.

26 Wirnsberger RM, de Vries J, Wouters EF, Drent M: Clinical presentation of sarcoidosis in The Netherlands: an epidemiological study. Neth J Med 1998; 53: 53-60.

27 McGrath DS, Daniil Z, Foley P et al: Epidemiology of familial sarcoidosis in the UK. Thorax 2000; 55: 751-754.

28 Brennan NJ, Crean P, Long JP, Fitzgerald MX: High prevalence of familial sarcoidosis in an Irish population. Thorax 1984; 39: $14-$ 18

29 Fite E, Alsina JM, Anto JM, Morera J: Sarcoidosis: a family contact study. Respiration 1998; 65: 34-39. 